\title{
Morphological and molecular characterization of downy mildew disease caused by Peronospora variabilis on Chenopodium album in Turkey
}

\author{
Merve Kara $^{1} \cdot$ Emine Mine Soylu ${ }^{1} \cdot$ Aysun Uysal $^{2} \cdot$ Şener Kurt ${ }^{1} \cdot$ Young-Joon Choi $^{3} \cdot$ Soner Soylu ${ }^{1}$
}

Received: 18 December 2019 / Accepted: 6 February 2020 / Published online: 12 February 2020

(C) Australasian Plant Pathology Society Inc. 2020

\begin{abstract}
White goosefoot (Chenopodium album) is a common weed being most frequent in several crops. In April 2018, typical symptoms of downy mildew disease were observed on the leaf surface of C. album in pea fields inspected in Hatay province of Turkey. Based on morphological characteristics, molecular sequencing and pathogenicity test, the pathogen was identified as Peronospora variabilis. To our knowledge, this is the first confirmed report of downy mildew caused by P. variabilis on C. album in Eastern Mediterranean region of Turkey.
\end{abstract}

Keywords Peronospora variabilis $\cdot$ Chenopodium album $\cdot$ Downy mildew

White goosefoot, Chenopodium album (also known as Common lambsquarters) is an important worldwide annual weed being most frequent in several winter vegetable crops such as carrot, parsley, potatoes and cereals (Netland et al. 2001). It is also a typical plant of areas, which are unused for 1 or 2 years (ruderal areas). C. album is also an important plant species due to its medicinal applications and nutritional characteristics (Galwey et al. 1990). Presence of this weed may cause severe reductions in crop yield and, in the most severe cases, complete loss of yield (Conley et al. 2003). Downy mildew is an economically important and widespread disease on C. album. During recent surveys on major fungal disease of pea, we have noticed severe downy mildew symptoms on C. album growing as a weed in several pea fields in Hatay province. Although 20 species of Peronospora have been reported to cause downy mildew on Chenopodium spp., identification and classification of the pathogen remain still uncertain due to its

Soner Soylu

soylu@mku.edu.tr

1 Department of Plant Protection, Faculty of Agriculture, Hatay Mustafa Kemal University, 31034 Antakya, Hatay, Turkey

2 Centre for Implementation and Research of Plant Health Clinic, Hatay Mustafa Kemal University, 31034 Antakya, Hatay, Turkey

3 Department of Biology, College of Natural Sciences, Kunsan National University, Gunsan 54150, South Korea taxonomic confusion (Choi et al. 2008). The purpose of this study was to analyse the morphological and molecular characterisation of the causal disease agent of downy mildew observed on C. album in Turkey.

During the disease surveys conducted in April 2018, typical symptoms of downy mildew disease were observed on the leaf surface of common weed species C. album in $60 \%$ of commercial pea fields inspected in Reyhanlı district $\left(36^{\circ} 22^{\prime}\right.$ $59.2^{\prime \prime} \mathrm{N} 36^{\circ} 31^{\prime} 29.8^{\prime \prime} \mathrm{E}$ ) of Hatay province of Turkey. Typical disease symptoms included the appearance of chlorotic spots or pink discoloration on the upper leaf surface of infected plants (Fig. 1A, B). These spots later turned necrotic. Dense tan or grey sporulation were frequently observed on the lower leaf surface (Fig. 1C). Leaves densely covered with a lot of conidiophores and conidia ultimately fallen off. When the infection is systemic, the plant showed dwarfing and yellowing. Infection during early development of the plant resulted in heavy defoliation.

The morphological characteristics of pathogen structures on heavily infected young leaves were examined by brightfield and Differential Interference Contrast (DIC) microscope (Olympus BX51, Japan) equipped with epifluorescence optics (Fig. 1D-F). Heavily infected young leaves were cleared in methanol/chloral hydrate and mounted in 50\% glycerol as described previously (Soylu and Soylu 2003). Conidia $(n=50)$ were olivaceous with a greyish tint, broadly ellipsoidal to ellipsoidal, sometimes appearing as obovoid or napiform due to pedicel, greatest width median, 25.0-35.0 $\mu \mathrm{m}$ long, 22.5-27.5 $\mu \mathrm{m}$ wide, with a length/width ratio of 1.2 

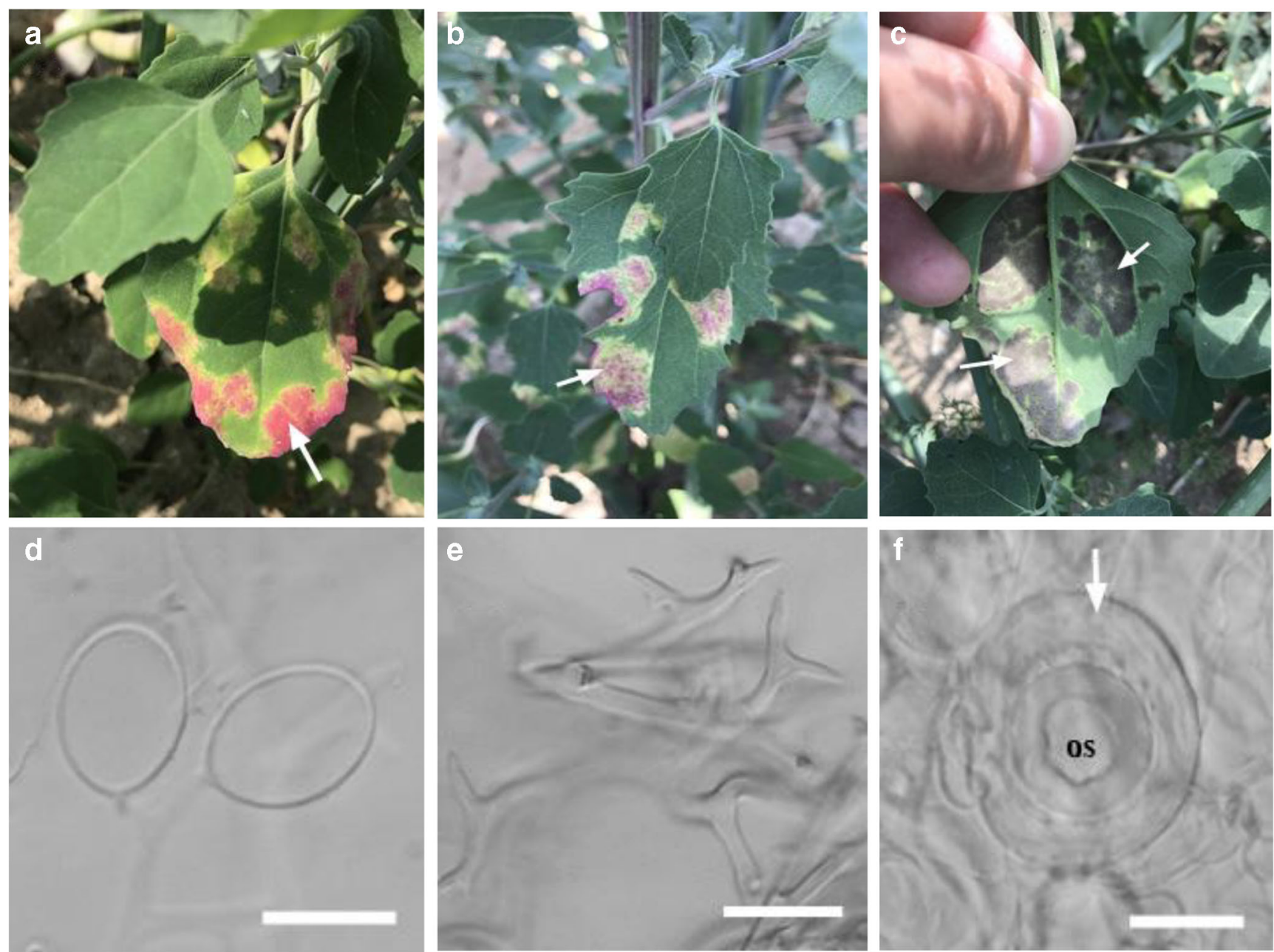

Fig. 1 Typical symptoms and morphological characteristics of downy mildew caused by Peronospora variabilis on Chenopodium album. Typical chlorotic spots or pink discoloration (arrow) on upper leaf surfaces (A and $\mathbf{B}$ ) and dense tan or grey oomycete matrix (arrow)

1.4 (Fig. 1D). Conidiophores $(n=50)$ emerging through stomata, were up to 10 in a fascicle, colorless, straight to slightly curved 230.0-550.0 $\mu \mathrm{m}$ long; trunk substraight to slightly curved, 110.0-370.0 $\mu \mathrm{m}$ long, basal end not differentiated, rarely bulbous, up to $15.0 \mu \mathrm{m}$ wide, $11.0-15.0 \mu \mathrm{m}$ wide at the base, 7.5-10.0 $\mu \mathrm{m}$ wide below the first branch, ultimate branchlets in pairs or single (Fig. 1E). Resting organ $(n=50)$ were often present and clearly visible as dark brown to yellowish dots on the lower leaf surface; oogonia subglobose to irregular, 32.0-55.0 $\mu \mathrm{m}$ diameter; oospores globose, 20.0$30.0 \mu \mathrm{m}$ diameter, golden brown to brown (Fig. 1F).

The morphological characteristics closely resembled those reported for downy mildew disease agent Peronospora variabilis (Choi et al. 2008). A dried herbarium of the infected plant was deposited in the Korea University herbarium (KUSF31532), Seoul, Korea.

Pathogenicity test was performed twice by inoculating the leaves of 10 healthy plant seedlings (3-weeks-old). Conidia were collected from fresh sporulating source plant leaves, consisting of conidiophores, conidia and oospores on the corresponding lower leaf surfaces $(\mathbf{C})$. Microscopic examination of $P$. variabilis showing (D) conidia, (E) ultimate branchlets on conidiophore, (F) oogonia (arrow) and oospore (os) in the infected C. album leaf. Bar $=20 \mu \mathrm{m}$

dispersed into sterilised water with a drop of $0.1 \%$ Tween 20 and mixed to produce a conidial suspension of $10^{6}$ conidia $/ \mathrm{ml}$. Seedlings were inoculated with conidial suspension by placing several droplets onto lower leaf surfaces. Five noninoculated plants served as controls. Inoculated and noninoculated plants were maintained where they covered in a growth chamber at $20^{\circ} \mathrm{C} / 15^{\circ} \mathrm{C}$ for $12 \mathrm{~h}$ day/night cycle and $95 \%$ relative humidity. Typical symptoms of downy mildew developed on the lower surfaces of inoculated leaves after 15 days. Non-inoculated plants remained symptomless. The pathogen present on the inoculated plants was morphologically identical to the original one observed on the diseased plants, fulfilling Koch's postulates.

To confirm the morphological identification, genomic DNA was extracted from conidiophores and conidia formed on leaves of infected host plants. The internal transcribed spacer (ITS) rDNA was amplified with primers ITS1-O and LR-0 and cytochrome oxidase II ( $\operatorname{cox} 2)$ mtDNA with primers $\operatorname{cox} 2$-F and cox2-RC4 (Choi et al. 2015). GenBank BLASTn 
search revealed that the ITS and cox 2 sequences of the Turkish isolate DMCa1 (Accession No. MK394004 and MK408662, respectively) were identical to ones of $P$. variabilis parasitic on C. album (EF614959 and KJ654199) and on C. quinoa (KF269542 and KF269666, respectively).

Based on morphological characteristics, molecular sequencing and pathogenicity test, the pathogen was identified as $P$. variabilis. Although disease agent was previously listed to occur on C. album in Ankara province (Gobelez 1962), to our knowledge, this is the first confirmation of downy mildew caused by $P$. variabilis on $C$. album in the Eastern Mediterranean region of Turkey. Disease agent was previously reported on Chenopodium spp. from different geographic origins including Europe, America and Asia (Choi et al. 2008; Choi et al. 2010; Farr and Rossman 2019).

\section{References}

Choi YJ, Denchev CM, Shin HD (2008) Morphological and molecular analyses support the existence of host-specific Peronospora species infecting Chenopodium. Mycopathologia 165:155-164
Choi YJ, Danielsen S, Lübeck M, Hong SB, Delhey R, Shin HD (2010) Morphological and molecular characterization of the causal agent of downy mildew on quinoa (Chenopodium quinoa). Mycopathologia 169:403-412

Choi YJ, Beakes G, Glockling S, Kruse J, Nam B, Nigrelli L, Ploch S, Shin HD, Shivas RG, Telle S, Voglmayr H, Thines M (2015) Towards a universal barcode of oomycetes-a comparison of the coxl and cox2 loci. Mol Ecol Resour 15:1275-1288

Conley SP, Stoltenberg DE, Boerboom CM, Binning LK (2003) Predicting soybean yield loss in giant foxtail (Setaria faberi) and common lambsquarters (Chenopodium album) communities. Weed Sci 51:402-407

Farr DF, Rossman AY (2019) Systematic mycology and microbiology laboratory, ARS, USDA. http://nt.ars-grin.gov/fungaldatabases/ Accessed 13 December 2019

Galwey NW, Leakey CLA, Price KR, Fenwick GR (1990) Chemical composition and nutritional characteristics of quinoa (Chenopodium quinoa Willd.). Food Sci Nutr 42F:245-261

Gobelez M (1962) La mycoflore de Turkue I. Mycopathol Mycol Appl 19:296-314

Netland J, Dutton LC, Greaves MP, Baldwin M, Vurro M, Evidente A, Einhorn G, Scheepens PC, French LW (2001) Biological control of Chenopodium album L. in Europe. Biocontrol 46:175-196

Soylu EM, Soylu S (2003) Light and electron microscopy of the compatible interaction between Arabidopsis and the downy mildew pathogen Peronospora parasitica. J Phytopathol 151:300-306 